\title{
Current Evidence on the Association between Mmp-7 (-181a>G) Polymorphism and Digestive System Cancer Risk
}

Pan Ke, Zhong De Wu, Hua Song Wen, Miao Xiong Ying, Huo Cheng Long and Liu Guo Qing*

Department of General Surgery, Xiang-Ya 2nd Hospital, Central South University, Chang-Sha, Hunan Province, China

\section{Abstract}

The matrix metalloproteinase (MMPs) can degrade various components of the extracellular matrix and its functional genetic polymorphisms may contribute to genetic susceptibility to many cancers. Up to now, the association between MMP-7 (-181A>G) and digestive system cancer risk remain inconclusive. To better understand the role of MMP-7 $(-181 \mathrm{~A}>\mathrm{G})$ genotype in digestive cancer development, we conducted this comprehensive meta-analysis encompassing 3,518 cases and 4,596 controls. Overall, the MMP-7 $(-181 \mathrm{~A}>\mathrm{G})$ polymorphism was associated with higher digestive system cancer risk in homozygote comparison (GG vs. $A A, O R=1.21,95 \% \mathrm{Cl}=1.12-1.60$ ) and dominant model (GG/GA vs. AA, OR=1.16, 95\% Cl=1.03-1.46). In subgroup analysis, this polymorphism was significantly linked to higher risks for gastric cancer (GG vs. $A A, O R=1.22,95 \% \mathrm{Cl}=1.02-1.46$; $G A$ vs. $A A, O R=1.82$, $95 \% \mathrm{Cl}=1.16-2.87$; GG/GA vs. AA, OR=1.13, 95\% $\mathrm{Cl}=1.01-1.27$; $\mathrm{GG}$ vs. GA/AA, OR=1.25, 95\% $\mathrm{Cl}=1.06-2.39$. We also observed increased susceptibility of colorectal cancer and ESCC in homozygote comparison (OR=1.13,95\% $\mathrm{Cl}=1.06-1.26)$ and heterozygote comparison $(\mathrm{OR}=1.45,95 \% \mathrm{Cl}=1.11-1.91)$ respectively. In the stratified analysis by controls, significant effects were only observed in population-based studies (GA vs. AA, OR=1.16, 95\% Cl=1.081.50; GA/AA vs. GG, OR=1.10,95\% $\mathrm{Cl}=1.01-1.72$ ). According to the source of ethnicity, a significantly increased risk was found among Asian populations in homozygote model ( $G G$ vs. AA, OR=1.40,95\% $\mathrm{Cl}=1.12-1.69$ ), heterozygote model (GA vs. $A A, O R=1.26,95 \% \mathrm{Cl}=1.02-1.51)$, and dominant model $(\mathrm{GG} / \mathrm{GA}$ vs. $\mathrm{AA}, \mathrm{OR}=1.18,95 \% \mathrm{Cl}=1.08$ 1.55). Our findings suggest that the MMP-7 $(-181 A>G)$ polymorphism may be a risk factor for digestive system cancer, especially among Asian population.

Keywords: MMP-7; Polymorphism; Digestive cancer; Meta-analysis

\section{Introduction}

The matrix metalloproteinase (MMPs) family comprise of more than 20 enzymes that are capable of degrading extracellular matrix proteins [1-3]. MMPs not only play important roles in physiological ECM remodelling, such as wound repair, tissue regeneration and embryo development, but are also associated with pathological conditions, such as arthritis, atherosclerosis and autoimmune blistering disorders of the skin. There is also growing evidence suggesting that MMPs can degrade various components of the extracellular matrix and are involved in cancer development by modulating cell proliferation, apoptosis, angiogenesis, and so on $[1,2]$ MMP7, localised on chromosome 11q21-q22, is one of the smallest members of the MMPs family, which can degrade elastin, proteogylcans, fibronectin and type IV collagen [3-23]. It also cleaves non-matrix substrates from the cell surface, such as E-cadherin, pro-tumour necrosis factor and Fas ligand. An A to $\mathrm{G}$ transition at -181 base pair position upstream of the transcription start site of MMP7 gene has been reported. The $\mathrm{G}$ allele has greater basal transcriptional activity than A allele in vitro experiment [24]. Over-expression of MMP7 has been shown to occur in a wide variety of cancers, including tumours of the oesophagus, stomach, colorectal, kidney and breast $[5,6]$, and this is correlated with tumor size, lymph node involvement and decreased survival. Recently, Many studies indicating that the common MMP-7 (-181A $>\mathrm{G})$ genetic polymorphism was correlated with cancer risk in many cancer types [7-22]. However, this relationship remains controversial in digestive system cancer, this meta-analysis was performed to evaluate the association between the MMP-7 $(-181 \mathrm{~A}>\mathrm{G})$ genetic polymorphism and digestive system cancer risk.

\section{Search Strategy and Data Extraction}

In this analysis, a literature research of the Pub Med database,

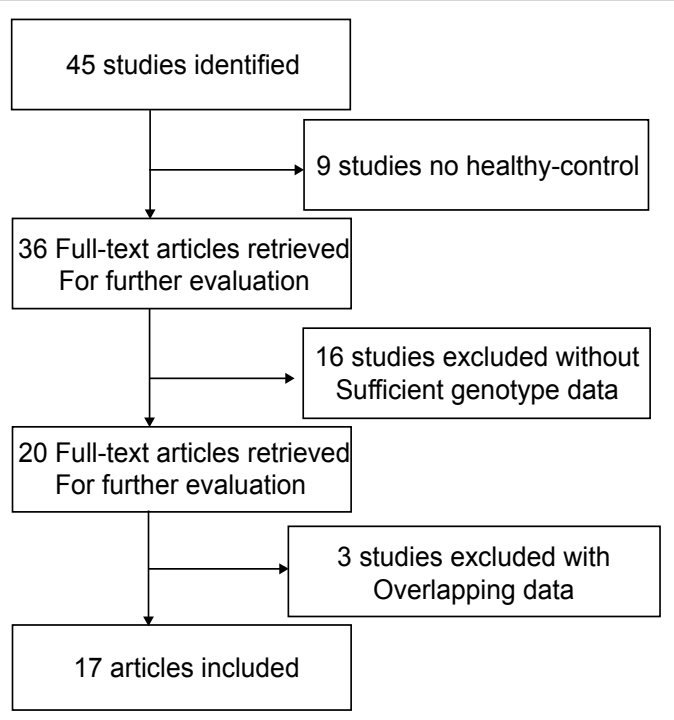

Figure 1: Flow diagram of study identification.

*Corresponding author: Guo Qing Liu, Department of General Surgery, Xiang-Ya 2nd Hospital, Central South University, Chang-Sha, Hunan Province, China, Tel: 86022-23340123-2071; E-mail: guangzhou26@yahoo.cn

Received February 28, 2013; Accepted March 29, 2013; Published April 02, 2013

Citation: Ke P, De Wu Z, Wen HS, Ying MX, Long HC, et al. (2013) Current Evidence on the Association between Mmp-7 (-181a>G) Polymorphism and Digestive System Cancer Risk. J Bioanal Biomed S9: 001. doi:10.4172/1948593X.S9-001

Copyright: @ $2013 \mathrm{Ke} \mathrm{P}$, et al. This is an open-access article distributed under the terms of the Creative Commons Attribution License, which permits unrestricted use, distribution, and reproduction in any medium, provided the original author and source are credited. 
Citation: Ke P, De Wu Z, Wen HS, Ying MX, Long HC, et al. (2013) Current Evidence on the Association between Mmp-7 (-181a>G) Polymorphism and Digestive System Cancer Risk. J Bioanal Biomed S9: 001. doi:10.4172/1948-593X.S9-001

Page 2 of 4

ISI Web of Knowledge, Medline, Embase and Google Scholar Search (up to date as of October, 2012) were conducted using the search terms including ("MMP7" or "matrix metalloproteinase 7"), "polymorphisms", "cancer", to obtain all genetic studies on the relationship of MMP-7 (-181A>G) polymorphism and cancer. We also used the combined phrases and a hand search of references of original studies on this topic. Figure 1 showed the flow diagram of study identification.

Data extraction was carried out independently by two investigators. We record the following information of each eligible study: the first author, year of publication, country of origin, genotyping methods, source of controls, number of cases and controls with different groups.

\section{Statistical Analysis}

The strength of relationship between MMP-7 (-181A>G) polymorphism and cancer was assessed by using Crude OR with $95 \%$ CI. We examined the association between the MMP-7 $(-181 \mathrm{~A}>\mathrm{G})$ polymorphism and digestive cancer risk using homozygote comparison (GG vs. AA), heterozygote comparison (GA vs. AA), dominant genetic model (GG + GA vs. AA) and recessive genetic model (GG vs. GA + AA). Between-study heterogeneity was evaluated by Q-test. Fixed effects model was used to pool the data when the P-value of Q-test $\geq 0.05$, otherwise, random-effects model was selected. Egger's test was used to

\begin{tabular}{|c|c|c|c|c|c|c|c|c|}
\hline Author & Year & Cancer type & Country & Ethnicity & Genotype assay & $\begin{array}{c}\text { Source of } \\
\text { Control }\end{array}$ & Case/Control & $P \ddagger$ \\
\hline Zhang & 2005 & Gastric & China & Asian & PCR-RFLP & Population & $201 / 350$ & Yes \\
\hline Kim & 2011 & Gastric & Korea & Asian & PCR-RFLP & Hospital & $153 / 326$ & Yes \\
\hline Malik & 2011 & Gastric & India & Asian & PCR-RFLP & Population & $108 / 195$ & Yes \\
\hline Sugimoto & 2008 & Gastric & Japan & Asian & PCR-RFLP & Hospital & $160 / 434$ & Yes \\
\hline Kubben & 2006 & Gastric & Holland & European & PCR-RFLP & Population & $79 / 169$ & Yes \\
\hline $\mathrm{Li}$ & 2008 & Gastric & China & Asian & PCR-RFLP & Population & $338 / 380$ & Yes \\
\hline Zhang & 2005 & ESCC & China & Asian & PCR-RFLP & Population & $258 / 350$ & Yes \\
\hline Malik & 2011 & ESCC & India & Asian & PCR-RFLP & Population & $135 / 195$ & Yes \\
\hline Lievre & 2006 & Colorectal & France & European & Tagman & Population & $596 / 565$ & Yes \\
\hline Dziki & 2011 & Colorectal & Poland & European & PCR-RFLP & Hospital & $184 / 205$ & Yes \\
\hline Ohtani & 2009 & Colorectal & Japan & Asian & PCR-RFLP & Hospital & $119 / 67$ & Yes \\
\hline Ghilardi & 2003 & Colorectal & Italy & European & Sequencing & Population & $58 / 111$ & Yes \\
\hline Woo & 2007 & Colorectal & Korea & Asian & PCR-RFLP & Population & $185 / 304$ & Yes \\
\hline Fang & 2010 & Colorectal & China & Asian & PCR-RFLP & Population & $252 / 237$ & Yes \\
\hline de Lima & 2009 & Colorectal & Brazil & South America & PCR-RFLP & Hospital & $108 / 113$ & Yes \\
\hline Vairaktaris & 2007 & Oral & Germany, Greek & European & PCR-RFLP & Population & $159 / 120$ & No \\
\hline Qiu & 2008 & Hepatocellular & China & Asian & PCR-RFLP & Population & $425 / 475$ & Yes \\
\hline
\end{tabular}

$\ddagger P$ value of Hardy-Weinberg equilibrium in controls; ESCC: esophageal squamous cell carcinoma

Table 1: Main characteristics of included studies in the meta-analysis.

\begin{tabular}{|c|c|c|c|c|c|c|c|c|c|}
\hline \multirow{2}{*}{ Study groups } & \multirow[b]{2}{*}{$\boldsymbol{N}^{*}$} & \multicolumn{2}{|c|}{ GG vs. AA } & \multicolumn{2}{|c|}{ GA vs. AA } & \multicolumn{2}{|c|}{ GG/GA vs. AA } & \multicolumn{2}{|c|}{ GG vs. GA/AA } \\
\hline & & OR $(95 \% \mathrm{Cl})$ & $P \$$ & OR $(95 \% \mathrm{Cl})$ & $P \$$ & OR (95\% Cl) & $P \$$ & OR (95\% Cl) & $P \$$ \\
\hline Total & 17 & $1.21(1.12-1.60) \ddagger$ & $<0.001$ & $1.06(0.99-1.36)$ & 0.536 & $1.16(1.03-1.46) \ddagger$ & $<0.001$ & $1.12(0.95-1.31) \ddagger$ & $<0.001$ \\
\hline \multicolumn{10}{|l|}{ Cancer type } \\
\hline Hepatocellular & 1 & $1.43(1.10-1.87)$ & 0.851 & $1.29(0.99-1.68)$ & 0.771 & $1.36(0.92-1.75)$ & 0.796 & $1.17(0.96-1.37)$ & 0.920 \\
\hline Gastric & 6 & $1.22(1.02-1.46)$ & 0.523 & $1.82(1.16-2.87)$ & 0.704 & $1.13(1.01-1.26)$ & 0.711 & $1.25(1.06-2.39)$ & 0.642 \\
\hline Colorectal & 7 & $1.13(1.01-1.26) \ddagger$ & 0.020 & $0.805(0.50-1.30) \ddagger$ & 0.006 & $0.86(0.54-1.35) \ddagger$ & 0.006 & $1.08(0.80-1.45)$ & 0.215 \\
\hline Esophagus & 2 & $1.00(0.24-4.30) \ddagger$ & $<0.001$ & $1.45(1.11-1.91)$ & 0.146 & 1.19(0.48-2.96)‡ & 0.002 & $0.81(0.27-2.39) \ddagger$ & $<0.001$ \\
\hline Oral & 1 & $0.73(0.38-1.39)$ & 0.312 & $1.09(0.26-4.55) \ddagger$ & 0.013 & $1.012(0.30-3.45) \ddagger$ & 0.026 & $0.88(0.56-1.36)$ & 0.478 \\
\hline \multicolumn{10}{|l|}{ Ethnicity } \\
\hline Asian & 12 & $1.40(1.12-1.69) \ddagger$ & $<0.001$ & $1.26(1.02-1.51) \ddagger$ & $<0.001$ & $1.18(1.08-1.55) \ddagger$ & $<0.001$ & 1.14(0.96-1.36)‡ & $<0.001$ \\
\hline European & 5 & 1.13(0.60-1.97)‡ & 0.070 & $0.98(0.69-1.37) \ddagger$ & 0.070 & 1.11(0.76-1.52)‡ & 0.029 & $1.01(0.73-1.51)$ & 0.154 \\
\hline \multicolumn{10}{|l|}{ Source of Control } \\
\hline Population-based & 5 & 1.19(0.91-1.90)‡ & $<0.001$ & $1.16(1.08-1.50) \ddagger$ & 0.029 & 1.10(1.01-1.72)‡ & $<0.001$ & $0.95(0.68-1.73) \ddagger$ & $<0.001$ \\
\hline Hospital-based & 12 & $1.25(1.01-1.74) \ddagger$ & 0.001 & $1.15(0.88-1.50) \ddagger$ & $<0.001$ & $1.14(0.84-1.54) \ddagger$ & $<0.001$ & $0.97(0.82-1.39$ & 0.150 \\
\hline
\end{tabular}

Abbreviations: $\mathrm{Cl}$, confidence interval; OR, odds ratio.

* Studies of comparison, \$P-value of Q-test for heterogeneity test, $¥$ Random model was used.

Table 2: Results of meta-analysis for MMP-7 (-181A>G) polymorphism and digestive cancer risks. 
assess the publication bias. $(\mathrm{P}<0.10$ was considered representative of statistical significance). All statistical analyses were performed using STATA11.0 software and Review Manage (v.5; Oxford, England).

\section{Results}

\section{Eligible studies}

The main characteristics of these studies are shown in table 1. Genotype distribution of the MMP-7 (-181A $>\mathrm{G})$ polymorphism among cancer cases and controls of the 16 studies are shown in table 2. The genotyping method contains the classic polymerase chain reaction-restriction fragment length polymorphism (PCR-RFLP) assay, DNA sequencing, Affymetrix and Taqman. Among all the studies, seven colorectal cancer studies, six gastric cancer studies, two esophageal squamous cell carcinoma studies, one oral carcinoma and one hepatocellular carcinoma were included. Twelve studies were Asian descent, four studies were Caucasian descent and one study was South America descent. Hospital based controls were carried out in 5 studies, while population based controls were carried out in twelve studies.

\section{Meta-analysis}

Overall, as shown in table 2, we observed that the MMP-7 $(-181 \mathrm{~A}>\mathrm{G})$ polymorphism increased the digestive system cancer risk in homozygote comparison (GG vs. AA, $\mathrm{OR}=1.21,95 \% \mathrm{CI}=1.12-1.60$ ) and dominant model (GG/GA vs. AA, OR=1.16, 95\% CI=1.03-1.46) when all the eligible studies were pooled into the meta-analysis (Table 2). In the subgroup analysis, we found that the MMP-7 (-181A>G) polymorphism elevates gastric cancer risk in all the four models (GG vs. $\mathrm{AA}, \mathrm{OR}=1.22,95 \% \mathrm{CI}=1.02-1.46$; GA $v$ s. $\mathrm{AA}, \mathrm{OR}=1.82,95 \%$ $\mathrm{CI}=1.16-2.87$; $\mathrm{GG} / \mathrm{AG}$ vs. $\mathrm{AA}, \mathrm{OR}=1.13,95 \% \mathrm{CI}=1.01-1.26$; $\mathrm{GG} / \mathrm{AG} v s$. $\mathrm{AA}, \mathrm{OR}=1.25,95 \% \mathrm{CI}=1.06-2.39$; Furthermore, we found significant association of MMP-7 (-181A $>\mathrm{G})$ polymorphism with ESCC and colorectal cancer in heterozygote comparison (GA vs. AA, OR=1.45, 95\% CI=1.11-1.91) and homozygote comparison (GG vs. AA, OR=1.13, 95\% CI=1.01-1.26) respectively. Compared with gastric cancer, ESCC and colorectal cancer, no significant associations were found in oral carcinoma and hepatocellular carcinoma.

We then evaluated the effects of the MMP-7 $(-181 \mathrm{~A}>\mathrm{G})$ polymorphism according to different ethnicities and different source of control. As shown in table 2, in the stratified analysis by ethnicity,

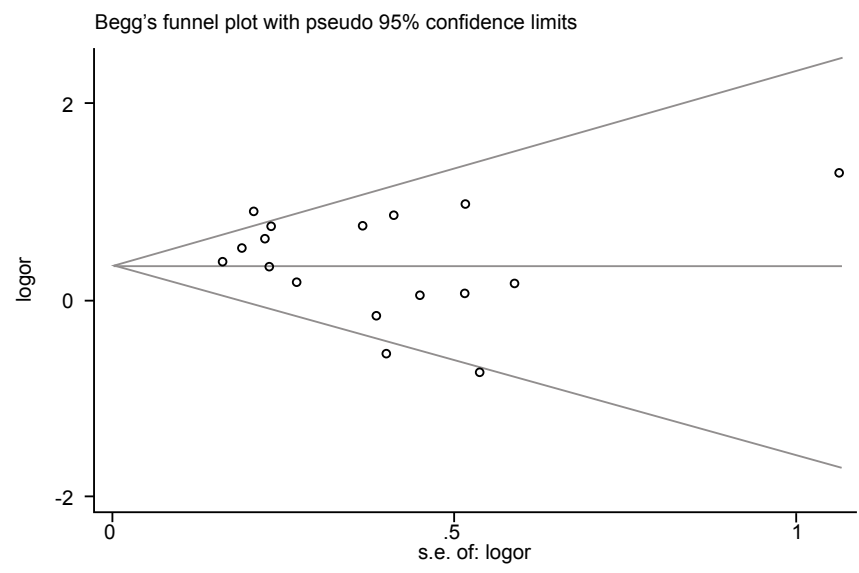

Figure 2: The funnel plot of oaverall GG vs. AA a significantly increased risk was found among Asian populations in heterozygote model (GA vs. AA, $\mathrm{OR}=1.26,95 \% \mathrm{CI}=1.02-1.51$ ), homozygote model (GG vs. AA, OR=1.40, 95\% $\mathrm{CI}=1.12-1.69$ ), and dominant model (GG/AG vs. AA, OR=1.18, 95\% CI=1.08-1.55). According to source of controls, significant effects were observed in population-based studies (GA vs. $\mathrm{AA}, \mathrm{OR}=1.16,95 \% \mathrm{CI}=1.08-1.50$, GG/AA vs. GG, OR=1.10, 95\% CI=1.01-1.72).

\section{Publication bias}

Both Begg's funnel plot and Egger's test were performed to assess the publication bias of the literature. The shape of the funnel plots did not reveal any evidence of obvious asymmetry in the overall meta-analysis (Figure 2 shows the funnel plot of overall GG vs. AA). Then Egger's test was performed to assess the publication bias of the literature. The results did not present any obvious evidence of publication bias in the subgroup analyses: for $\mathrm{GG} v$ s. AA $\mathrm{P}=0.576$, $\mathrm{GA}$ vs. $\mathrm{AA} \mathrm{P}=0.872 \mathrm{GG}+\mathrm{GA}$ vs. AA $\mathrm{p}=0.675, \mathrm{GG} v s$. GA+AA $\mathrm{P}=0.721$.

\section{Discussion}

The result of this meta-analysis involving 3,518 cases and 4,596 controls suggested that the MMP-7 - $181 \mathrm{~A} / \mathrm{G}$ polymorphism was overall significantly associated with digestive system cancer risk, especially in Asian population.

Recently, Malik MA conducted one study indicating that individuals who living in the Kashmir Valley carrying -181 GG genotype were related to high risk of gastric cancer [9]. Besides, Ghilardi et al. observed the $-181 \mathrm{~A} / \mathrm{G}$ polymorphism was associated with increased risk of colorectal cancer development [17]. However, Peng et al. performed a meta-analysis and suggested the association between MMP7-181 A G and increased cancer risk was found in the gastric cancer subgroup, no significant difference was found in the colorectal cancer subgroup [23].

In this meta-analysis, significant association was found between the MMP7 -181 A/G polymorphism and risk of gastric cancer. Besides, the association was more significant in the recessive model compared with the dominant model. Functional analysis in vitro has shown that nuclear proteins bind with higher affinity to the $-181 \mathrm{G}$ allele than to the $-181 \mathrm{~A}$ allele and promoter activity variation of the $-181 \mathrm{G}$ allele was about 2-3 times than that of the -181 A allele, which may induce elevation of the protein expression, so individuals with GG genotype could have a higher risk of the gastric cancer than with GA genotype. For ESCC and colorectal cancer, the significant associations were just found in the dominant model and homozygote model respectively. We also found Asians with GG genotype had higher risk of cancer compared to Caucasians. Several factors such as environmental factors and different genetic backgrounds might contribute to the difference. Furthermore, inconsistent results were observed between hospitalbased studies and population-based studies. Controls in populationbased studies were more representative of general population than controls from hospital-based studies.

As in all research, our study has limitations. First, the controls were not uniformly defined. Second, studies involved in different ethnicities are warranted to estimate the effects of this functional polymorphism on digestive system cancer risk. Third, due to the original data of the eligible studies are not available. It is difficult to evaluate the roles of diet, alcohol consumption, and smoking status in digestive cancer development.

In conclusion, our meta-analysis suggested that the MMP7 -181 
Citation: Ke P, De Wu Z, Wen HS, Ying MX, Long HC, et al. (2013) Current Evidence on the Association between Mmp-7 (-181a>G) Polymorphism and Digestive System Cancer Risk. J Bioanal Biomed S9: 001. doi:10.4172/1948-593X.S9-001

$\mathrm{A} / \mathrm{G}$ polymorphism may be a risk factor in digestive system cancer development, especially among Asian population. Large well-designed studies are needed to validate our findings in the future.

\section{References}

1. Lia $Y$, Jina X, Kangb S, Wang Y, Dub H, et al. (2006) Polymorphisms in the promoter regions of the matrix metalloproteinases $-1,-3,-7$, and -9 and the risk of epithelial ovarian cancer in China. Gynecol Oncol 101: 92-96.

2. Singh $\mathrm{H}$, Jain $\mathrm{M}$, Mittal $\mathrm{B}(2008) \mathrm{MMP}-7(-181 \mathrm{~A}>\mathrm{G})$ promoter polymorphisms and risk for cervical cancer. Gynecol Oncol 110: 71-75.

3. Wu S, Lu S, Tao H, Zhang L, Lin W, et al. (2011) Correlation of polymorphism of IL-8 and MMP-7 with occurrence and lymph node metastasis of early stage cervical cancer. J Huazhong Univ Sci Technolog Med Sci 31: 114-119.

4. Yi YC, Chou PT, Chen LY, Kuo WH, Shih-Chu Ho E, et al. (2010) Matrix metalloproteinase-7 (MMP-7) polymorphism is a risk factor for endometrial cancer susceptibility. Clin Chem Lab Med 48: 337-44.

5. Hodi FS, Minm MC, Soiffer RJ, Haluska FG, Butler M, et al. (2003) Biologic activityof cytotoxic $\mathrm{T}$ lymphocyte-associated antigen 4 antibodyblockade in previously vaccinated metastatic melanoma andovarian carcinoma patients. Proc Natl Acad Sci 100: 4712-4717.

6. Greenwald RJ, Oosterwegel MA, Diane van der Woude, Kubal A, Mandelbro DA, et al. (2002) CTLA-4 regulates cell cycle progression during a primaryimmune response. Eur J Immunol 32: 366-373.

7. Zhang J, Jin X, Fang S, Wang R, Li Y, et al. (2005) The functional polymorphism in the matrix metalloproteinase-7 promoter increases susceptibility to esophageal squamous cell carcinoma, gastric cardiac adenocarcinoma and non-small cell lung carcinoma. Carcinogenesis 26: 1748-1753.

8. Kim JH, Pyun JA, Lee KJ, Cho SW, Kwack KB (2011) Study on Association between Single Nucleotide Polymorphisms of MMP7, MMP8, MMP9 Genes and Development of Gastric Cancer and Lymph Node Metastasis. Korean J Gastroenterol 58: 245-251.

9. Malik MA, Zargar SA, Mittal B (2011) Role of the metalloproteinase-7 (181A>G) polymorphism in gastric cancer susceptibility: a case control study in Kashmir valley. Asian Pac J Cancer Prev 12: 73-76.

10. Sugimoto M, Furuta T, Kodaira C, Nishino M, Yamade M, et al. (2008) Polymorphisms of matrix metalloproteinase-7 and chymase are associated with susceptibility to and progression of gastric cancer in Japan. J Gastroenterol 43 : 751-761.

11. Kubben FJ, Sier CF, Meijer MJ, van den Berg M, van der Reijden JJ, et al (2006) Clinical impact of MMP and TIMP gene polymorphisms in gastric cancer. Br J Cancer 95: 744-751.
12. Li JY, Tian MM, Zhao AL (2008) Polymorphism in the promoter region of the metalloproteinase-7 increases susceptibility and risk of metastasis of gastric adenocarcinoma. Gastroenterology 134: A603.

13. Malik MA, Sharma KL, Zargar SA, Mittal B (2011) Association of matrix metalloproteinase-7 $(-181 \mathrm{~A}>\mathrm{G})$ polymorphism with risk of esophageal squamous cell carcinoma in Kashmir Valley. Saudi J Gastroenterol 17: 301 306.

14. Lievre A, Milet J, Carayol J, Le Corre D, Milan C, et al. (2006) Genetic polymorphisms of MMP1, MMP3 and MMP7 gene promoter and risk of colorectal adenoma. BMC Cancer 6: 270.

15. Dziki L, Przybyłowska K, Majsterek I, Trzciński R, Mik M, et al. (2011) A/G Polymorphism of the MMP-7 Gene Promoter Region in Colorectal Cancer. Pol PrzeglChir 83: 622-626.

16. Ohtani H, Maeda N, Murawaki Y (2009) Functional polymorphisms in the promoter regions of matrix metalloproteinase-2,-3,-7,-9 and TNF- alpha genes and the risk of colorectal neoplasm in Japanese. YonagoActamedica 52: 47-56.

17. Ghilardi G, Biondi ML, Erario M, Guagnellini E, Scorza R (2003) Colorecta carcinoma susceptibility and metastases are associated with matrix metalloproteinase-7 promoter polymorphisms. Clin Chem 49: 1940-1942.

18. Woo M, Park K, Nam J (2007) Clinical implications of matrix metalloproteinase-1 $-3,-7,-9,-12$, and plasminogen activator inhibitor-1 gene polymorphisms in colorectal cancer. J Gastroenterol Hepatol 22: 1064-1070.

19. Fang WL, Liang WB, He H, Zhu Y, Li SL, et al. (2010) Association of Matrix Metalloproteinases 1,7 , and 9 Gene Polymorphisms with Genetic Susceptibility to Colorectal Carcinoma in a Han Chinese Population. DNA Cell Biol 29: 657661.

20. de Lima JM, de Souza LG, da Silva ID (2009) E-cadherin and metalloproteinase-1 and -7 polymorphisms in colorectal cancer. Int J Biol Markers 24: 99-106.

21. 21.Qiu W, Zhou G, Zhai Y, Zhang X, Xie W, et al. (2008) No Association of MMP-7, MMP-8, and MMP-21 Polymorphisms with the Risk of Hepatocellular Carcinoma in a Chinese Population. Cancer Epidemiol Biomarkers Prev 17: 2514-2518.

22. Vairaktaris E, Serefoglou Z, Yapijakis C, Vylliotis A, Nkenke E, et al. (2007) High gene expression of matrix metalloproteinase-7 is associated with early stages of oral cancer. Anticancer Res 27: 2493-2498.

23. Peng B, Cao L, Ma X, Wang W, Wang D, et al. (2010) Meta-analysis of association between matrix metalloproteinases 2, 7 and 9 promoter polymorphisms and cancer risk. Mutagenesis 25: 371-379.

24. Jormsjo S, Whatling C, Walter DH, Zeiher AM, Hamsten A, et al. (2001) Allelespecific regulation of matrix metalloproteinase-7 promoter activity is associated with coronary artery luminal dimensions among hypercholesterolemic patients. Arterioscler Thromb Vasc Biol 21: 1834-1839. 